\title{
Structure and sequence of the mouse Bmp6 gene
}

\author{
Stephen E. Gitelman, ${ }^{1,2}$ Michael Kobrin, ${ }^{5}$ Angela Lee, ${ }^{5}$ Victor Fet, ${ }^{6}$ Karen Lyons, ${ }^{6}$ Brigid L.M. Hogan, ${ }^{6,7}$ \\ Rik Derynck ${ }^{2,3,4,5}$
}

${ }^{1}$ Department of Pediatrics, Box 0136, MU East Rm 405, 500 Parnassus Avenue, University of California at San Francisco, San Francisco, California 94143, USA

${ }^{2}$ Department of Growth and Development, University of California at San Francisco, San Francisco, California 94143, USA

${ }^{3}$ Department of Anatomy, University of California at San Francisco, San Francisco, California 94143, USA

${ }^{4}$ Programs in Cell Biology and Developmental Biology, University of California at San Francisco, San Francisco, California, 94143, USA

${ }^{6}$ Department of Cell Biology, Vanderbilt University Medical Center, Nashville, Tennessee 37232, USA

${ }^{7}$ Howard Hughes Medical Institute, Vanderbilt University Medical Center, Nashville, Tennessee 37232, USA

Received: 23 July 1996 / Accepted: 30 October 1996

The transforming growth factor- $\beta$ (TGF- $\beta$ ) superfamily consists of structurally related, secreted disulfide-bonded dimers that modulate cellular growth and differentiation. Many of these factors have been shown to inhibit the proliferation or promote apoptosis of various cell types, to induce expression of various extracellular matrix proteins, and to modulate cell differentiation along particular lineages (reviewed in Derynck 1994; Kingsley 1994; Roberts and Sporn 1990). The largest group of related factors within this superfamily, which has been referred to as the decapentaplegic/ vg-1-related proteins (DVR; Lyons et al. 1991), comprises the bone morphogenetic proteins (BMPs), Xenopus vegetal-1(vg-1), nodal, dorsalin, at least five factors referred to as growthdifferentiation factors (GDFs), and three Drosophila homologs, decapentaplegic (dpp), 60A, and screw. Within this family, the largest subgroup consists of BMPs-5, -6 (also known as Vgr-1), -7 (also known as osteogenic protein-1, or OP-1), $-8 \mathrm{a}$ (OP-2), and $-8 \mathrm{~b}$ (OP-3), all of which are homologous to the ancestral Drosophila protein $60 \mathrm{~A}$.

Inactivation of the Bmp5 and Bmp7 genes has provided preliminary insights into the developmental role of these proteins, with distinctive phenotypes of the mutant mice (Kingsley et al. 1992; Luo et al. 1995). We have begun to characterize the function of BMP-6 as a prototype factor of this subgroup. This cDNA was originally isolated from a murine embryonic cDNA library by screening under low stringency with a Xenopus vg-1 cDNA probe, and the corresponding protein was named Vgr-1 (Lyons et al. 1989a). cDNAs for the human and bovine homologs of Vgr-1 were subsequently isolated and were named BMP-6 (Celeste et al. 1990), although no bone morphogenetic activity was originally reported for this protein. Extensive in situ hybridization and immunohistochemical analyses have localized BMP-6 mRNA and protein expression in the central nervous system, suprabasal layer of the epidermis, and hypertrophic cartilage (Gitelman et al. 1994; Jones et al 1991; Lyons et al. 1989b; Wall et al. 1993). We have overexpressed this factor in $\mathrm{CHO}$ cells and have shown that, when these cells are introduced subcutaneously into nude, athymic mice, the secreted BMP- 6 protein induces ectopic cartilage and bone in a pattern that recapitulates endochondral bone formation (Gitelman et al. 1994). We have also overexpressed BMP-6 within a pluripotent mesenchymal cell line and have shown that the protein acts as an autocrine factor that induces osteoblastic differentiation in vitro (Gitelman et al. 1995).

The Bmp6 gene has been mapped previously to murine Chromosome (Chr) 13, $2.2 \pm 1.5 \mathrm{cM}$ distal to the Friend MuLV integrations site (Dickinson et al. 1990), and the human gene has been

Correspondence to: S.E. Gitelman mapped to a related region on Chr 6p (Hahn et al. 1992). To further understand the mechanisms of transcriptional regulation of the endogenous Bmp6 gene and to manipulate its expression in vivo, we have isolated the mouse Bmp6 gene and characterized its structure and sequence.

A 129/Sv murine genomic library in pCOS-EMBL3 (gift of A. Frischauf) and a mouse genomic library in $\lambda$ Charon $4 \mathrm{~A}$ were screened with the mouse Vgr-1 cDNA under high stringency hybridization conditions. Two overlapping cosmids and five phage were purified through subsequent rounds of screening. The clones were mapped, and restriction fragments hybridizing to the Vgr-1 cDNA were then subcloned into pUC119 or pBluescript (Stratagene, La Jolla, Calif.) for sequencing. We sequenced the coding regions of the Bmp6 gene, as well as all intron-exon boundaries and $5^{\prime}$ and $3^{\prime}$ untranslated regions. The exon sequences corresponded to those previously reported for the BMP-6 cDNA (Gitelman et al. 1994). The gene consists of seven coding exons, all flanked by canonical intron/exon splicing sequences (see GenBank Accession \#U73515-U75320).

The gene structures for a few members of the TGF- $\beta$ superfamily are known. The genomic organization of Bmp6 most closely resembles that of the genes for Bmp7/OP-1 and Bmp8/OP2, which belong to the same subfamily as Bmp6 (Fig. 1) (Ozkaynak et al. 1992). Both the Bmp7 and Bmp8a genes contain seven exons, and comparison of the sequences and intron-exon boundaries with those of Bmp6 reveals a conservation of identical intron-exon structure with boundaries at corresponding positions. These results suggest that the other members of this subgroup may have similar gene organizations and support their evolution from a common ancestral gene. The genes for the three TGF- $\beta$ isoforms also contain seven exons (Derynck et al. 1987, 1988) (Fig. 1). However, closer inspection reveals that their coding sequences are distributed differently among the exons when compared with the Bmp6, Bmp7, and Bmp8a genes than among those of the TGF- $\beta$ isoforms: the corresponding exons are of different sizes, and the mature protein is encoded by three full exons and a portion of a fourth in the Bmp6, Bmp7, and Bmp8a genes, as opposed to two full exons and a portion of a third for TGF- $\beta$.

Within a separate subgroup of the BMP family, Bmp2 and $B m p 4$ are closely related to each other and are in turn related to the dpp gene in Drosophila. The Bmp2 gene consists of 3 exons, two of which encode the precursor protein (Feng et al. 1994). Similarly, the Bmp4 gene also has two coding exons with intron-exon boundaries at identical corresponding positions as in the Bmp2 gene (Feng et al. 1995). In contrast to Bmp2, the Bmp4 gene has three noncoding exons; two of these are first exons for part of the 5 '-noncoding region, and their incorporation into the mRNA de- 
A

$\begin{array}{lccccc} & \text { dpp } & \text { BMP-2 } & \text { BMP-4 } & \text { TGF- } \beta 1,2,3 & \text { BMP-6 } \\ \text { Coding Exons } & 2 & 2 & 2 & 7 & 7 \\ \text { Non-coding Exons } & 5 & 1 & 3 & -- & - \\ \text { B } & & & & & \\ \text { BMP-6, }-\mathbf{7},-\mathbf{8}\end{array}$

$200 \mathrm{bp}$

Fig. 1. A. Comparison of gene structures of the different TGF- $\beta$ superfamily members: $d p p, B m p 2, B m p 4, T g f \beta 1,-\beta 2,-\beta 3, B m p 7, B m p 8 a$, and now Bmp6. Noncoding exons refer to possible exons from the $5^{\prime}$ flanking DNA which have been shown to serve as alternate promoters. B. Coding exons for some members of the TGF- $\beta$ superfamily, grouped according to both structural and sequence homology. Exons encoding the precursor region are designated with open boxes, and the mature region is shown by black boxes. $5^{\prime}$ and $3^{\prime}$ untranslated regions and introns are not represented.

pends on the differential transcriptional initiation from one of the two Bmp4 promoters (Feng et al. 1995). The Bmp2 and Bmp4 genes bear close similarities to the structure of the Drosophila dpp gene, which contains two coding exons at positions corresponding to the intron-exon structures of the Bmp2 and Bmp4 genes (St. Johnston et al. 1990). In addition, the $d p p$ gene has several alternate noncoding $5^{\prime}$ exons, and these alternate promoters are regulated in both a developmental and tissue-specific manner. Comparison of the Bmp6 gene structure with those of the Bmp2, Bmp4, and $d p p$ genes reveals little similarity in the localization of the intron-exon structures, even though the deduced BMP-6 protein sequence has homology to these members of the BMP group. The implications of these findings for the evolution of these two subgroups of genes within the TGF- $\beta$ superfamily are unclear at this time, and may be clarified upon characterization of the gene structure of the Drosophila 60A gene, which is homologous to the genes for Bmp5, Bmp6, Bmp7, and Bmp8.

We have examined the 1730 base pairs of $5^{\prime}$ flanking sequence of the Bmp6 gene for possible transcription factor binding sites, and some putative sites are shown in Fig. 2. In the mouse Bmp4 gene, a COUP-TFI response element precedes one of the transcriptional initiation sites, and COUP-TFI functions as a silencer of Bmp4 expression in fetal rat calvarial osteoblasts (Feng et al. 1995). In addition, some potential binding sites for homeobox transcription factors are noted in the $5^{\prime}$ flanking region. These findings suggest a connection between developmentally regulated transcription factors and Bmp4 expression. Preliminary functional analysis of the Bmp2 gene has shown that a putative homeoboxlike factor may be important in enhancing gene transcription, suggesting that developmentally controlled transcription factors might also determine the spatial and temporal expression of the Bmp2 gene (S.E. Harris, personal communication). Bmp6 expression might also be modulated by a developmentally regulated transcription factor. One potential site for such regulation is through the putative bicoid binding site (Fig. 2). Another possible site is through the basic helix loop helix (bHLH) transcription factor MyoD, since a MyoD binding site can be found in the Bmp6 promoter sequence (Fig. 2). Thus, a close correlation might exist between MyoD expression, or a related basic helix loop helix transcription factor, and Bmp6 expression in differentiating mesenchymal cells. Further analysis of Bmp6 transcription will be required to determine the elements central to its unique developmental and tissue-specific patterns of expression.

Acknowledgments. This research was funded by National Institutes of Health (NIH) Grant 1 K08 AR01897-01 to S. Gitelman; Genentech, NIH Center Grant P50-DE10306 to R. Derynck; and NIH grant CA48799 to B.M.L. Hogan. B.M.L. Hogan is an Investigator of the Howard Hughes Medical Institute.

\section{References}

Celeste AJ, Iannazzi JA, Taylor RC, Hewick RM, Rosen V, Wang EA, Wozney JM (1990) Identification of transforming growth factor B family members present in bone-inductive protein purified from bovine bone. Proc Natl Acad Sci USA 87, 9843-9847

Derynck R (1994) Transforming growth factor $\beta$. In The Cytokine Handbook 2nd ed. Angus Thompson ed. (Boston: Academic Press) pp 319342

Derynck R, Rhee L, Chen EY, Tilburg AV (1987) Intron-exon structure of the human transforming growth factor- $\beta$ precursor gene. Nucleic Acid Res 15, 3188-3189

Derynck R, Lindquist PB, Lee A, Wen D, Tamm J, Graycar JL, Rhee L, Mason AJ, Miller DA, Coffey RJ, Moses HL, Chen EY (1988) A new type of transforming growth factor- $\beta$ TGF- $\beta$. EMBO J 7, 3737-3743

Dickinson ME, Kobrin MS, Silan CM, Kingsley DM, Justice JM, Miller DA, Ceci JD, Lock LF, Lee A, Buchberg AM, Siracusa LD, Lyons KM, Derynck R, Hogan BLM, Coperland NG, Jemkins NA (1990) Chromosomal localization of seven members of the TGF-b superfamily suggests close linkage to several morphogenetic mutant loci. Genomics 6, 505520

Feng JQ, Harris MA, Ghosh-Choudhury N, Feng M, Mundy GR, Harris SE (1994) Structure and sequence of mouse bone morphogenetic protein-2 gene (BMP-2): comparison of the structures and promoter regions of BMP-2 and BMP-4 genes. Biochim Biophys Acta 1218, 221-224

Feng JQ, Chen D, Cooney AJ, Tsai M-J, Harris MA, Tsai SY, Feng M, Mundy GR, Harris SE (1995) The mouse bone morphogenetic protein-4 gene. J Biol Chem 270, 28364-28373

Gitelman SE, Kobrin MS, Ye J-Q, Lopez AR, Lee A, Derynck R (1994)

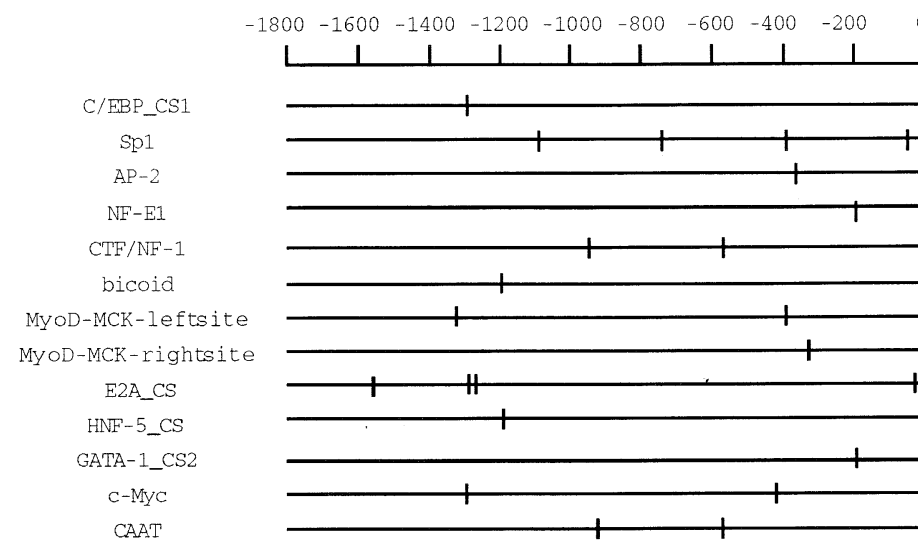

TKNNGYAAK CCGCCC CCSCRGG

MYWATCWY

AGCCAAT

ATTTAATCCA

CACGTG

CACCTG

RCAGNTG

TRTTTGY

WGATAMS

CACGTG

GCCAAT
Fig. 2. Schematic diagram of location of transcription factor binding sites. The numbering across the top of the figure refers to nucleotide distance from the transcriptional initiation codon. The putative transcription factor binding sites are shown vertically in the column on the left, and the consensus binding site sequences are shown on the right-hand column. The abbreviations in these sequences are: $\mathrm{N}$, any of the four nucleotides; $\mathrm{R}$, A or G; Y, C or T; M, A or C; K, G or T; W, A or $\mathrm{T} ; \mathrm{S}, \mathrm{C}$ or $\mathrm{G}$. 
Recombinant vgr-1/BMP-6-expressing tumors induce fibrosis and endochondral bone formation in vivo. J Cell Biol 126, 1595-1609

Gitelman SE, Kirk M, Ye J-Q, Filvaroff EH, Kahn AJ, Derynck R (1995) Vgr-1/BMP-6 induces osteoblastic differentiation of pluripotent mesenchymal cells. Cell Growth Differ 6, 827-836

Hahn GV, Cohen RB, Wozney JM, Levitz CL, Shore EM, Zasloff MA, Kaplan FS (1992) A bone morphogenetic protein subfamily: chromosomal localization of human genes for BMP5, BMP6, and BMP7. Genomics $14,759-762$

Jones CM, Lyons KM, Hogan BLM (1991) Involvement of bone morphogenetic protein-4(BMP-4) and vgr-1 in morphogenesis and neurogenesis in the mouse. Development 111, 531-542

Kingsley DM (1994) The TGF-beta superfamily: new members, new reports, and new genetic tests of function in different organisms. Genes Dev 8, 133-146

Kingsley DM, Bland AE, Grubber JM, Marker PC, Russell LB, Copeland NG, Jenkins NA (1992) The mouse short ear skeletal morphogenesis locus is associated with defects in a bone morphogenetic member of the TGF- $\beta$ superfamily. Cell 71, 399-410

Luo G, Hofmann C, Bronkers ALJJ, Sohocki M, Bradley A, Karsenty G (1995) BMP-7 is an inducer of nephrogenesis, and is also required for eye development and skeletal patterning. Genes Dev 9, 2808-2820

Lyons K, Graycar JL, Lee A, Hashmi S, Lindquist PB, Chen EY, Hogan
BLM, Derynck R (1989a) Vgr-1, a mammalian gene related to Xenopus $\mathrm{Vg}-1$, is a member of the transforming growth factor beta gene superfamily. Proc Natl Acad Sci USA 86, 4554-4558

Lyons KM, Pelton RW, Hogan BLM (1989b) Patterns of expression of murine Vgr-1 and BMP-2 RNA suggest that transforming growth factorbeta-like genes coordinately regulate aspects of embryonic development. Genes Dev 3, 1657-1668

Lyons KM, Jones CM, Hogan BLM (1991) The DVR gene family in embryonic development. Trends Genet 7, 408-412

Ozkaynak E, Schnegelsberg PNJ, Jin DF, Clifford GM, Warren FD, Drier EA, Oppermann H (1992) Osteogenic protein-2: a new member of the transforming growth factor-b superfamily expressed early in embryogenesis. J Biol Chem 267, 25220-25227

Roberts AB, Sporn MB (1990) The transforming growth factor-betas. In Handbook of Experimental Pharmacology. Peptide Growth Factors and Their Receptors, M.B. Sporn, A.B. Roberts, eds. pp 419-472

St. Johnston RD, Hoffmann FM, Blackman RK, Segal D, Grimaila R, Padgett RW, Irick HA, Gelbart WM (1990) Molecular organization of the decapentaplegic gene in Drosophila melanogaster. Genes Dev 4, 1114-1127

Wall NA, Blessing M, Wright CVE, Hogan BLM (1993) Biosynthesis and in vivo localization of the decapentaplegic-Vg-related protein, DVR-6 (bone morphogenetic protein-6). J Cell Biol 120, 493-502 